http://jmscr.igmpublication.org/home/ ISSN (e)-2347-176x ISSN (p) 2455-0450

crossref DOI: https://dx.doi.org/10.18535/jmscr/v9i12.11

\title{
Prevalence and Spectrum of Bleeding Disorders in Females at Tertiary Care Centre
}

\author{
Authors
}

\section{Dr Indira Sahu, Dr Suman Ruhela}

\begin{abstract}
Bleeding disorders in females is rare but when present, usually present with menorrhagia, mucocutaneous bleeding or per rectal bleed. We retrospectively analysed the spectrum of bleeding disorders in females referred to our laboratory for the workup of bleeding disorders.

Methodology: Females who were referred to our laboratory for workup of bleeding disorders were asked to fill form enquiring a detailed menstrual, family and significant past history including drug intake history. Samples were collected in Na citrate vacuitaners for testing the coagulation parameters.

Results: Out of 607 patients studied for bleeding disorders we found 10(2.1\%) females (age range 3 months-69years) with deranged coagulation profile (Isolated increase in APTT). In 8/10 (80\%) factor VIII was found reduced which on futher mixing studies 3 of them showed presence of inhibitors, 3/10 females had reduced $v W F$ level so labelled as $v W D$, other $2 / 10$ had reduced factor VIII so were labelled as mild Hemophillia. 2/10 (20\%) were found to have reduced factor IX level but all three females were less than 6 month of age.

Conclusion: Heavy menstrual bleeding may be the only clinical manifestation of an inherited bleeding disorder in a substantial proportion of women and we suggest that all such patients should be investigated for Underlying hemostatic defects. This will not only help in diagnosis but also in proper management for future hemostatic challenges.
\end{abstract}

\section{Introduction}

Bleeding disorders in females is rare but when present, usually present with menorrhagia, mucocutaneous bleeding or per rectal bleed. Women with heavy menstruation might not seek medical advice due to unawareness of symptoms and are poorly investigated and are left undiagnosed. While not all women with HMB have an underling bleeding disorder, the challenge for primary care providers, obstetricians and gynaecologists is identifying those women and girls who should be referred to an HTC for evaluation. ${ }^{[1]}$ This can be complicated by failure to recognize abnormal bleeding symptoms. Some women may not recognize that their bleeding is abnormal, particularly if there are other family members with similar symptoms. Additionally, HMB is often managed by obstetricians, gynaecologists or primary care providers who may not think to consider a bleeding disorder. Bleeding disorders have significant impact on woman's reproductive health \& quality of life. ${ }^{[1]}$ Some challenges to diagnosing women with bleeding disorders include lack of access to appropriate laboratory testing and issues around disease classification and nomenclature. Most of females 
are carrier of the disease, many of these have clotting level between $30 \%$ and $70 \%$ of normal \& do not usually suffer from severe bleeding. However some carriers have less than $30 \%$ level of factor VIII or factor IX hence considered mild haemophilia. ${ }^{[2]}$ Added to this further development of inhibitors to factor VIII sometimes give false assumption of patient suffering from haemophilia. ${ }^{[3]}$

We retrospectively analysed the spectrum of bleeding disorders in females referred to our laboratory for the workup of bleeding disorders although Our study population may not be representative of women in the general population with heavy periods since general practitioners do not refer all such women to hospital.. Efforts have been undertaken to address these challenges, including the development and validation of bleeding assessment tools and strategies to clarify diagnostic thresholds and algorithms.

\section{Aim}

To analyse the spectrum of bleeding disorders in females and provide an algorithm for diagnosing bleeding disorders in females.

\section{Material and Method}

It was a retrospective study, data was collected from the medical records of Advanced haematology and HLA laboratory, SMS Medical college from January 2018 to December 2020. Females of all age group were included in the study. The registration form were filled that included a detailed history of bleeding symptoms, duration, menstrual history, reproductive outcomes, family and drug history .Samples were collected in $\mathrm{Na}$ citrate vacuitaners for testing the coagulation parameters. (PT,APTT). [Figure 1] Then females with isolated prolonged aPTT results were separated and were further evaluated for coagulation factor assay( Factor VIII and factor IX ). Further In females with reduced factor VIII mixing studies were performed to rule out pseudohemophilia. Also von Willebrand factor was assayed to rule out von Willebrand Disease.

\section{Results}

A total of 607 patient studied we found 10(2.1\%) females with disarranged coagulation profile (isolated increase in APTT).In 8/10 females (70\%) factor VIII was found reduced, further mixing studies were done and 3 of them showed presence of inhibitors and were diagnosed as pseudohemophilia. $3 / 10 \quad(30 \%)$ females had reduced vWF level and thus were labelled as having von Willebrand disease and were advised molecular studies. Rest 2/10 (20\%) had reduced factor VIII in mild range and hence were diagnosed as mild Haemophilia A. 2/10 (20\%) patients were found with reduced factor IX level, all three females were below the age of 12 months (one being 3 months, other 7 month and third being10 month age). [Figure 2] However on repeated test after attaining age of 1 year showed normal coagulation.

\section{Discussion}

Bleeding disorders in females although rare but do exist. We have shown that undiagnosed inherited bleeding disorders, especially in the mild form, are an underlying cause in a substantial number of women with menorrhagia. Therefore, we suggest that patients with menorrhagia and without obvious pelvic abnormalities should be routinely tested for these disorders-particularly von Willebrand's disease-before they undergo invasive procedures. A diagnosis of an inherited bleeding disorder would lead to rapid and effective treatment of the menorrhagia. Kadir et al. observed the presence of inherited bleeding disorders in 26 of 150 (17\%) Caucasian women with menorrhagia ${ }^{[4]}$ These included vWD in 18, FXI deficiency in four, mild vWD and FXI deficiency in one, combined $v W D$, FXI and FX deficiency in one, carrier of haemophilia A gene in one and platelet dysfunction in one. Dilley et al. ${ }^{[5]}$ analysed 121 women with menorrhagia and inherited bleeding disorders were diagnosed in $10.7 \%$ of these patients. VWD was the commonest disorder and was diagnosed in $8 \%$ cases. It was also noted in some studies that the 
similarity in the bleeding characteristics in women with inherited bleeding disorders and those without is striking. Trauma isthe event most predictive of an inherited bleeding disorder ${ }^{[6]}$. Others have reported that menorrhagia is the dominant symptom of an inherited bleeding disorder in women ${ }^{[7]}$. In our study a total of 607 patient (both male and female) were studied and we found $10(2.1 \%)$ females with disarranged coagulation profile, though study size is very small compared to other studies but our study showed $30 \%$ women to have pseudohemophilia i.e. inhibitors to factor VIII , 30\% female had decreased VWD and rest $20 \%$ were having reduced Factor VIII level being labelled as having mild Hemophillia A. Kadir et al found that $80 \%$ of women who were diagnosed to have vWD and $67 \%$ of those who had FXI deficiency had a history of bruising. ${ }^{[8]}$ Edlund et al. identified mild inherited bleeding most of which were vWD in as high as $37 \%$ of women with menorrhagia.[9]In our study we found $2.1 \%$ females with disarranged coagulation profile, but $20 \%$ of these females were below age of 1 year (below this age coagulation factors are not mature to the adult level and attain normal level by 1 year) which became normal by 1 year of age so remaining was $1 \%$ females with bleeding disorder. Sample size of our study was relatively small compared to other studies, this may be so because bleeding symptoms are variable and factor deficiency levels are mild most of females don't even approach for investigation and are left undiagnosed.

\section{Conclusion}

In present study an effort was made to evaluate bleeding disorders in females and it has been suggested that those female patients who present with menorrhagia and bleeding from other sites without any discernable cause require proper workup for congenital coagulation disorders .

1) Check APTT whether increased isolated then check F VIII and F IX level

2) Full menstrual history, family history, and any drug intake history.
3) Mixing studies to rule out pseudohemophilia.

4) vWF assay to rule out vWD

5) Age is also important as coagulation factors mature by age of one year.

\section{Limitation}

Our findings have limitation due to relatively small sample size. The bleeding tendencies of females with F VIII \& F IX deficiency still remains unclear. The lack of awareness of this uncommon inherited bleeding disorder and a paucity of good diagnostic facilities add to the problem. Limitation to molecular \& mutational studies is further limitation to our study.

\section{References}

1. Guelcher CJ, Chase J, Pollard D. Women and girls with heavy menstrual bleeding and inherited bleeding disorders: A call to action for the Haemophilia Treatment Centre Nurse. Haemophilia. 2021;27 (Suppl. 3):82-86.

2. James PD. Women and bleeding disorders: diagnostic challenges. Hematology AM SOC HEMATOL Educ Program; 2020; 2020(1):547-52.

3. Ma AD, Carrizosa D. Acquired factor VIII inhibitors: pathophysiology and treatment. Hematology Am Soc Hematol Educ Program. 2006:432-7.

4. Kadir RA, Economides DL, Sabin CA, Owens D, Lee CA. Frequency of inherited bleeding disorders in women with menorrhagia. Lancet 1998; 351: 485-9.

5. Dilley A, Drews C, Miller $\mathrm{C}$ et al. von Willebrand disease and other inherited bleeding disorders in women with diagnosed menorrhagia. Obstetrics Gynaecol 2001; 97: 630-6.

6. Sramek A, Eikenboom JCJ, Briet E, Vandenbroucke JP, Rosendaal FR. Usefulness of patient interview in bleeding disorders. Arch Intern Med 1995; 155: 1409-15. 
7. Lee CA. Women and inherited bleeding disorders. Menstrual issues. Semin Hematol 1999; 36(suppl 4):21-7.

8. Kadir RA, Aledort LM. Obstetrical and gynaecologicalbleeding: a common presenting symptom. Clin Lab Haematol 2000; 22(supp 1): 12-6.

9. Edlund M, Blomback M, Von schoult ZB, Andersson $\mathrm{O}$. On the value of menorrhagia as a predictor for coagulation disorders. Am J Hematol 1996; 53: 234-8. 